\title{
CLINICAL EFFECTS OF THE LOCAL DRUG DELIVERY OF 0.5\% AZITHROMYCIN GEL IN TREATMENT OF CHRONIC PERIODONTITIS AMONG SMOKERS VERSUS NON SMOKERS
}

\author{
Jasmine Kaur ${ }^{1}$, Viniti Goel ${ }^{2}$, Ranjan Malhotra ${ }^{3}$, Vishakha Grover ${ }^{4}$ \\ ${ }^{1}$ PG Student, Department of Periodontology, National Dental College and Hospital, Punjab, India \\ ${ }^{2}$ Reader, Department of Periodontology, National Dental College and Hospital, Punjab, India \\ ${ }^{3}$ Principal, Professor \& Head, Department of Periodontology, National Dental College and Hospital, Punjab, India \\ ${ }^{4}$ Reader, Department of Periodontology, Dr. Harvansh Singh Judge Institute of Dental Sciences \& Hospital, Chandigarh, India
}

\begin{abstract}
\begin{tabular}{r|r} 
ABSTRACT \\
ABT
\end{tabular}
Background: Along with conventional periodontal surgical therapy, local delivery of antibiotics may provide more effective treatment in smokers by targeting tissue-invasive bacteria. The aim of this randomized, clinical trial was to evaluate the adjunctive effects of subgingivally delivered $0.5 \%$ azithromycin (AZM) as an adjunct to scaling and root planing (SRP) in the treatment of chronic periodontitis in smokers versus non smokers. Methods: 38 sites in patients of chronic periodontitis were randomized and categorized into two treatment groups: Group 1 consisted of 19 sites in patients who were smokers and Group 2 consisted of 19 sites in non smokers, who received Scaling and Root Planing (SRP) plus $0.5 \%$ azithromycin gel Local drug delivery. Clinical parameters were recorded at baseline, 1 and 2 months. They included probing depth (PD) and clinical attachment level (CAL) and percentage bone fill. Results: Azithromycin resulted in significant improvements in both the groups. Mean decrease in PD in non smokers by the end of 2 months was $3.903 \mathrm{~mm}$ and in smokers was $3.917 \mathrm{~mm}$. Gain in CAL in non smokers by the end of 2 months was $3.879 \mathrm{~mm}$ and in smokers it was $3.920 \mathrm{~mm}$. Mean bone fill at one month for smokers was $15.86 \%$ and was $26.58 \%$ at 2 months. In non-smokers the mean bone fill was $17.19 \%$ at 1 month and $24.03 \%$ at 2 months. Conclusions: When compared to the non smokers, the adjunctive use of $0.5 \%$ AZM resulted in similar improvement in clinical outcome in the treatment of chronic periodontitis among smokers. Local drug delivery of Azithromycin gel contributed to decrease in probing pocket depth, gain in clinical attachment level and in alveolar bone. The apparent bone regeneration also raises the intriguing possibility that Azithromycin encourages bone formation once tissue inflammation has subsided.
\end{abstract}

Keywords: Azithromycin, Local Antimicrobial Therapy, Smoking, Percentage Bone Fill, Chronic Periodontitis

\section{INTRODUCTION:}

Chronic periodontitis is defined as an inflammatory disease of the toothsupporting tissues caused by specific microorganisms residing in the subgingival biofilm. This chronic inflammation causes progressive destruction of the periodontal ligament and alveolar bone, resulting in pocket formation, gingival recession or both.' The aetiology of periodontitis is multifactorial, but it is an infection and bacterial species are the primary aetiologic agents. The importance of bacteria in the aetiology of periodontal pockets has been clearly established; as a result, therapy is necessarily directed at controlling the bacterial flora associated with the periodontium/tooth interface. ${ }^{2,3}$

Antibiotics have been used as adjunctive agents in the management of periodontal diseases for many years and their role has recently been reviewed. The evidence for their efficacy in the management of various types of periodontitis is conflicting and there is little consensus as to the optimum type, 
dosage, duration of treatment, and mix of antibiotic when combined therapy is used. ${ }^{4}$

The repeated, long-term use of systemic antibiotics is fraught with potential dangers, including resistant strains and superimposed infections, and problems such as lack of patient compliance. Therefore, the local administration of antimicrobials provides a useful solution to these complications. ${ }^{4}$

Smoking is a major risk factor in the initiation and progression of periodontal disease. ${ }^{5}$ In general, studies have shown that smoking increases the risk for developing periodontal disease by two to five fold, and these effects seem to be dose dependent. ${ }^{6,7}$ There is a fairly well established biologic rationale for the negative effects of cigarette smoking on periodontal tissues. ${ }^{8,9}$ These include: immuno-suppressive effect on the host, adversely affecting host-parasite interactions, impaired peripheral blood polymorphonuclear leukocyte motility, chemotaxis, and phagocytosis, decreased antibody production, alterations in the subgingival vascular oxygen tension, increased adhesion of bacteria to epithelial cells, reduced proliferation, migration, and attachment of fibroblast to the root surface, and impaired collagen synthesis and protein secretion. ${ }^{10,11,12}$

As a result, smokers tend to have a less favourable therapeutic response to non-surgical or surgical therapy. ${ }^{13,14}$ Generally, smokers demonstrate less PD reduction and CAL gain following therapy. ${ }^{15}$ This may be due to the fact that smokers tend to harbour more periodontal pathogens before and even after therapy, which may contribute to inferior results. Additionally, it has been shown consistently that smokers tend to accumulate more plaque than non-smokers, which may explain, in part, their inability to sustain PD reduction. ${ }^{16}$

Azithromycin is a semisynthetic, acid-stable antibiotic, and it represents the prototype of a novel class of macrolides named azalides. ${ }^{17,18}$ It consists of a 15-membered lactone ring containing a tertiary amino group, attached to two sugar moieties and differs from erythromycin by an amino-substituted, expanded macrolide nucleus. ${ }^{19-20}$ These structural differences give acid stability and peculiar pharmacokinetic properties to azithromycin, consisting of high extraction from the blood into target tissues. Furthermore, azithromycin has a wide antimicrobial spectrum of action towards anaerobic bacteria as well as against Gram-negative bacilli, and this activity supports its use in the treatment of odontogenic infections. ${ }^{21,22}$

Few randomized-controlled clinical trials have reported different degrees of success with the use of AZM in the treatment of mild to moderate chronic periodontitis, or aggressive periodontitis (AgP).

However, only a few previous studies have evaluated the adjunctive benefit of this antibiotic in the treatment of smokers versus non-smoker subjects with advanced chronic periodontitis. Previous studies have reported improved clinical and microbiological outcomes with local drug delivery (LDD) of azithromycin and similar benefits with LDD of AZM in the treatment of chronic periodontitis in smokers. ${ }^{2}$ To the best of our knowledge, there is no published literature on in situ gel using $0.5 \%$ AZM for direct placement in the periodontal pocket for the treatment of chronic periodontitis in smokers and non smokers.

Therefore, the aim of this randomized clinical trial was to evaluate clinically the effect of the local drug delivery of $0.5 \%$ Azithromycin gel in the management of chronic periodontitis in smokers and non smokers as assessed by parameters viz vertical probing depth, clinical attachment level, radiographic bone height and to compare the treatment of chronic periodontitis with scaling and root planing followed by local drug delivery of $0.5 \%$ Azithromycin gel in smokers and non smokers.

\section{PROCEDURE}

\section{Sample Size Calculation}

This study was designed to compare the clinical effects of the treatment of smoker and non-smoker 
patients suffering from chronic Periodontitis with SRP + LDD of $0.5 \%$ AZM gel. The ideal sample size to ensure adequate power suffering from chronic periodontitis for this clinical trial was calculated considering differences of at least $1 \mathrm{~mm}$ between groups for mean CAL gain in initially deep periodontal sites $(\mathrm{PD}+5 \mathrm{~mm})$.

It was also determined that the standard deviation of CAL change at deep sites was $1.0 \mathrm{~mm}$ based on previous studies of smokers receiving. SRP combined with LDD of $0.5 \%$ AZM gel. Based on these calculations, it was defined that 13 sites per group would be necessary to provide an $85 \%$ power with a of 0.01 based on a two-sided test. Considering an attrition of $20 \%$, it was established that at least 19 sites should be included in each treatment group.

Patient Population: Inclusion and Exclusion Criteria

Patients suffering from chronic periodontitis were selected from those visiting the outpatient department of Periodontology and Oral Implantology, National Dental College and Hospital, Derabassi (Punjab). Systemically healthy subjects in the age group of 25-60 years (both males and females) were enrolled in the investigation.

Patient recruitment started in June 2014 and was completed at the end of July 2014.

Inclusion Criteria:

1. Patients with chronic periodontitis having pocket depth more than $5 \mathrm{~mm}$ at minimum one site.

2. Patients in the age group of 25-60 years (both males and females)

3. Systemically healthy patients.

4. Cooperative patients who can be motivated for further oral hygiene instructions and willing to participate in the study.

\section{Exclusion Criteria}

1. Patients are using any antiplaque or chemotherapeutic agent.
2. Known allergy or hypersensitivity to Azithromycin or Macrolide group of antibiotics.

3. Pregnant or/and lactating patients.

4. Patients on antibiotics or anti inflammatory drugs for the last 3 months.

5. Patients who had undergone any periodontal treatment within 6 months prior to the study.

Smoking history was obtained using a detailed questionnaire. A subject was classified as current smoker if he or she regularly smoked more than 10 cigarettes/day for a minimum of 5 years. Non-smokers were subjects who had never smoked. Former smokers, i.e. subjects who had previously been smokers but had stopped their habit, were excluded. ${ }^{23}$

After subject enrolment by an examiner, subjects were assigned to Group 1 (smokers) and Group 2 (nonsmokers).

A custom-made acrylic stent to provide a more reliable estimate of CAL and a University of North Carolina no. 15 colour-coded periodontal probe (HuFriedy, Chicago, IL, USA) were used to standardize the measurement of clinical parameters. All pre- and posttreatment clinical parameters were recorded by one examiner in both the groups.

Formulation of $0.5 \%$ AZM in situ gel

After intensive in vitro investigations for optimization and stability at the collaborative centre, the following formulation was developed. PLGA(Poly lactic-co-Glycolic Acid) in situ gel was prepared as described by Shah et al. ${ }^{24}$

An accurately weighed amount of PLGA (PLGA7502A Purac Biomaterials, PURASORBR, Gorinchem, the Netherlands) was placed in a glass vial, and the required amount of biocompatible solvent (N-Methyl2-pyrrolidone) was added. The vial was heated to $60^{\circ} \mathrm{C}$ and agitated using a magnetic stirrer on an electromagnetic heater to obtain a clear solution. A weighed amount of AZM was added to the above 
polymer solution and dissolved completely to obtain a homogeneous phase of polymer, solvent and drug. The formulation constituents for AZM in situ gel were Nmethyl-2-pyrrolidinone as the biocompatible solvent and PLGA copolymer in a ratio of $75: 25$, with a molecular weight of $72000(72 \mathrm{kd})$ and a microenvironment $\mathrm{pH}$ of 7.4 .

For preparing $200 \mathrm{gm}$ of $0.5 \%$ Azithromycin gel other constituents were:

Carbomer 940 IP Gelling Agent (As base) -1.6 gm

EDTA(LR Grade)( as chelating agent) -200mg

$\mathrm{NaOH}$ (LR Grade) $\quad-285 \mathrm{mg}$

Propylene Glycol IP $\quad-10 \mathrm{gm}$

Glycerin IP -30gm

Cardamom Flavour(BIS) -400mg

Benzalkonium Chloride Solution (50\%) IP - $-0.00004 \mathrm{ml}$

Subjects from both the groups were given thorough oral hygiene instructions. SRP was performed at baseline until the root surface was considered smooth and clean by the operator. All sites were treated with SRP followed by immediate $0.5 \%$ AZM gel local drug delivery.

\section{Local drug delivery}

For standardization only, $0.2 \mathrm{ml}$ prepared AZM gel was injected into the periodontal pockets using a blunt cannula. Periodontal dressing was applied after delivery of the drug. After placement of the in situ gel, patients were instructed to refrain from chewing hard or sticky foods, brushing near the treated areas, or using any interdental aids for 1 week. Adverse effects were noted at recall visits, and any supragingival deposits were removed.

In other words, patients were treated as a whole for their periodontal disease. No antibiotics or antiinflammatory agents were prescribed after treatment. Clinical parameters, including PD and CAL (Figure 1) and Radiographic bone height (Figure 2) were recorded at baseline and 1 month and 2 months post treatment (Figure 3 and 4). Oral hygiene instructions were reinforced and subjects were asked to refrain from using any other oral hygiene aid apart from brushing twice daily.

Apart from clinical evaluation, subjective evaluation was also undertaken at each visit using a questionnaire relating to any taste and flavour alteration or any adverse effect, after the treatment.
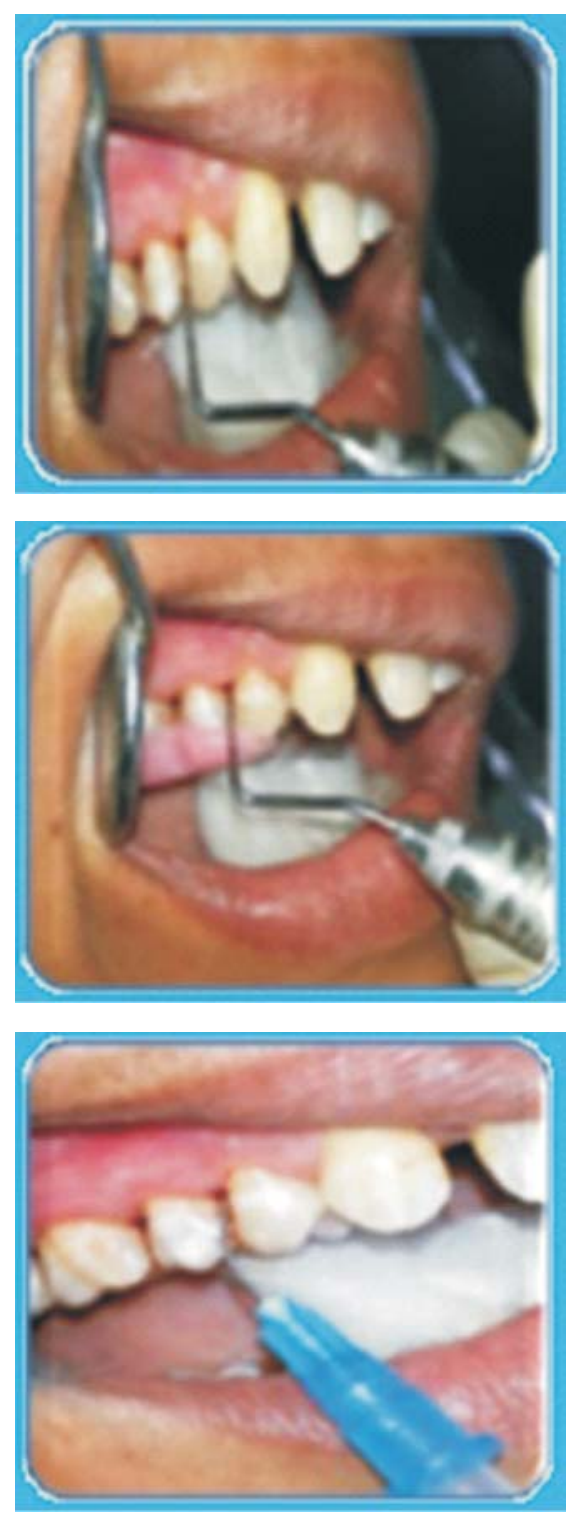

Figure 1: Showing Probing Pocket Depth, Clinical Attachment Level recording and Local Drug Delivery of $0.5 \%$ Azithromycin Gel 


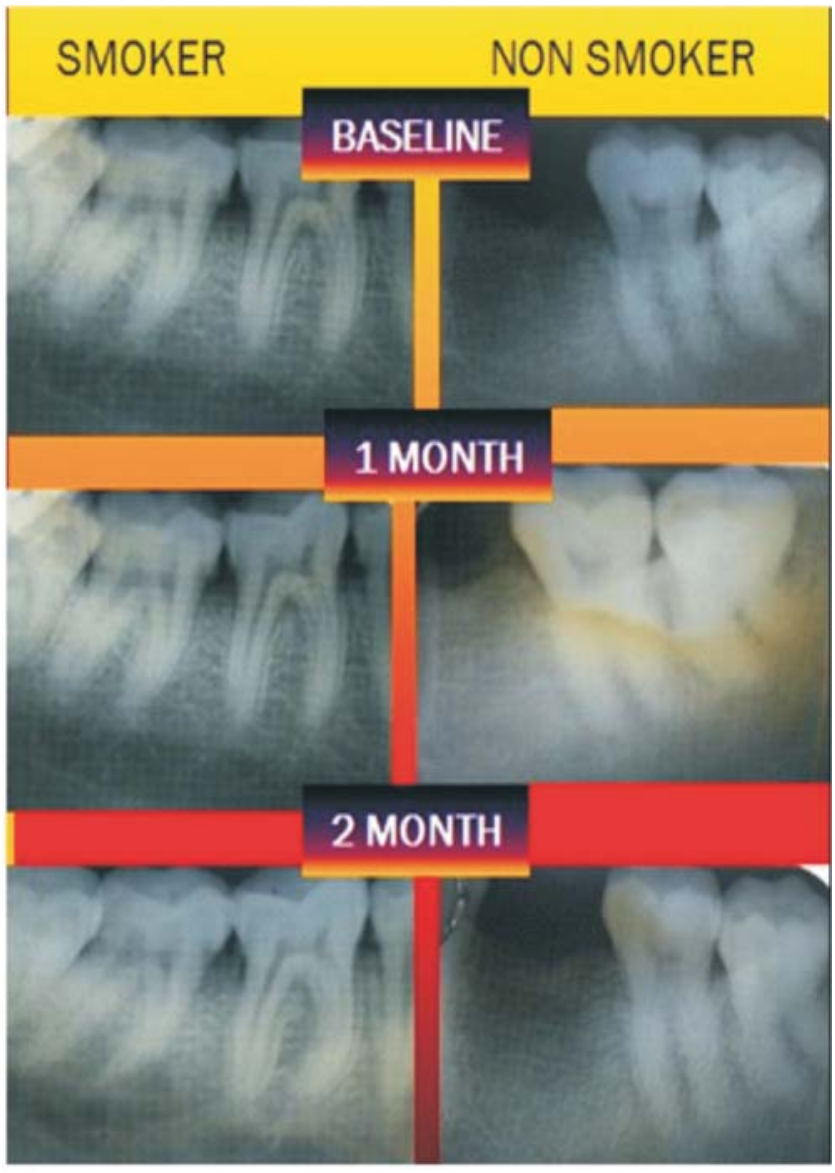

Figure 2: Showing Radiographs At Baseline, One Month And 2 Months post operatively

\section{RESULTS}

38 sites were evaluated in the study. No adverse reaction was observed in any subject from both the groups, and no patient reported any discomfort. The CAL gain was taken as the primary outcome and all the other clinical parameters were taken as secondary outcomes.

Mean probing depth at baseline in smokers was $5.73 \mathrm{~mm}$ and in non smokers it was $5.26 \mathrm{~mm}$. Mean value of clinical attachment level at baseline was $6.31 \mathrm{~mm}$ for non-smokers and for smokers the mean clinical attachment level was $5.36 \mathrm{~mm}$ (Table 1). Mann Whitney test was employed for intergroup evaluation of probing depth and gain in clinical attachment level at baseline, 1 month and 2 months, and it was found that the population from both the groups were similarly distributed (Table 2).

Mean bone fill at one month for smokers was $15.86 \%$ and was $26.58 \%$ at 2 months. In non-smokers the mean bone fill was $17.19 \%$ at 1 month and $24.03 \%$ at 2 months (Table 3). The Wilcoxon signed-rank test was used to compare the pocket probing depth and clinical attachment level and there was a significant improvement in pocket probing depth and clinical attachment level from baseline to one month and two months (Table 4). Mean decrease in PD in non smokers by the end of 2 months was $3.903 \mathrm{~mm}$ and in smokers was $3.917 \mathrm{~mm}$. Gain in CAL in non smokers by the end of 2 months was $3.879 \mathrm{~mm}$ and in smokers it was $3.920 \mathrm{~mm}$. Mean bone fill at one month for smokers was $15.86 \%$ and was $26.58 \%$ at 2 months. Percentage bone fill was significant ( $p$ value 0.002 for smokers and 0.001 for non smokers) from baseline to 2 months and 1 month to two months in both the groups. (Table 5) Mann-Whitney test was employed, it was seen that the change in pocket probing depth was significant from baseline to 1 month ( $p$ value:0.297)and baseline to two months (pvalue 0.246) (Table 6) On subjective

Table 1: NPar Tests

\begin{tabular}{|l|l|l|l|l|}
\hline Group & & $\mathbf{N}$ & $\begin{array}{l}\text { Mean } \\
(\mathbf{m m})\end{array}$ & $\begin{array}{l}\text { Std. Deviation } \\
(\mathbf{m m})\end{array}$ \\
\hline \multirow{4}{*}{$\begin{array}{l}\text { non } \\
\text { smokers }\end{array}$} & PPD BL & 19 & 5.7368 & .99119 \\
\cline { 2 - 5 } & CAL BL & 19 & 6.6316 & 1.46099 \\
\cline { 2 - 5 } & PPD 1 m & 19 & 3.8947 & .45883 \\
\cline { 2 - 5 } & CAL 1 m & 19 & 4.3158 & .94591 \\
\cline { 2 - 5 } & PPD 2 m & 19 & 3.1053 & .45883 \\
\cline { 2 - 5 } & CAL 2 m & 19 & 3.9474 & 1.31122 \\
\hline Smokers & PPD BL & 19 & 5.2632 & .56195 \\
\cline { 2 - 5 } & CAL BL & 19 & 5.3684 & .49559 \\
\cline { 2 - 5 } & PPD 1 m & 19 & 3.8947 & .73747 \\
\cline { 2 - 5 } & CAL 1 m & 19 & 3.8947 & .73747 \\
\cline { 2 - 5 } & PPD 2 m & 19 & 3.1053 & .56713 \\
\cline { 2 - 5 } & CAL 2 m & 19 & 3.1053 & .56713 \\
\hline
\end{tabular}

(Where, PPD:POCKET Probing Depth,CAL : Clinical Attachment Level,BL: Baseline,1m: One Month Recall Visit,2m: Two Months Recall Visit) 
Table 2: Mann-Whitney Test

\begin{tabular}{|l|l|l|l|l|l|l|}
\hline & PPD BL & CAL BL & PPD 1 m & CAL 1 m & PPD 2m & CAL 2m \\
\hline Mann-Whitney U & 132.000 & 86.000 & 177.500 & 139.000 & 179.500 & 106.500 \\
\hline Wilcoxon W & 322.000 & 276.000 & 367.500 & 329.000 & 369.500 & 296.500 \\
\hline Z & -1.601 & -2.958 & -.102 & -1.310 & -.038 & -2.434 \\
\hline Asymp. Sig. (2-tailed) & .109 & $.003 * *$ & .919 & .190 & .970 & $.015^{*}$ \\
\hline Exact Sig. [2*(1-tailed Sig.)] & $.163(\mathrm{a})$ & $.005(\mathrm{a})$ & $.931(\mathrm{a})$ & $.234(\mathrm{a})$ & $.977(\mathrm{a})$ & $.030(\mathrm{a})$ \\
\hline
\end{tabular}

Table 3: Group Statistics T-Test

\begin{tabular}{|l|l|l|l|l|l|}
\hline & Group & N & Mean & Std. Deviation & Std. Error Mean \\
\hline \multirow{2}{*}{ \%BONE FILL 1m } & non smokers & 19 & 15.8605 & 13.97560 & 3.20622 \\
\cline { 2 - 6 } & smokers & 19 & 17.1921 & 19.03426 & 4.36676 \\
\hline \multirow{2}{*}{$\%$ BONE FILL 2m } & non smokers & 19 & 24.0395 & 16.06560 & 3.68570 \\
\cline { 2 - 6 } & smokers & 19 & 26.5895 & 20.01893 & 4.59266 \\
\hline
\end{tabular}

(Where, PPD:POCKET Probing Depth,CAL : Clinical Attachment Level,BL: Baseline,1m: One Month Recall Visit,2m: Two Months Recall Visit)

Table 4:Test Statistics: Wilcoxon Signed Ranks Test

\begin{tabular}{|l|l|l|l|l|l|l|l|}
\hline Group & & $\begin{array}{l}\text { PPD 1 m - } \\
\text { PPD BL }\end{array}$ & $\begin{array}{l}\text { PPD 2m - } \\
\text { PPD BL }\end{array}$ & $\begin{array}{l}\text { PPD 2m - } \\
\text { PPD 1 m }\end{array}$ & $\begin{array}{l}\text { CAL 1 m - } \\
\text { CAL BL }\end{array}$ & $\begin{array}{l}\text { CAL 2m - } \\
\text { CAL BL }\end{array}$ & $\begin{array}{l}\text { CAL 2m - } \\
\text { CAL 1 m }\end{array}$ \\
\hline \multirow{2}{*}{$\begin{array}{l}\text { Non } \\
\text { smokers }\end{array}$} & Z & $-3.893(\mathrm{a})$ & $-3.903(\mathrm{a})$ & $-3.419(\mathrm{a})$ & $-3.876(\mathrm{a})$ & $-3.879(\mathrm{a})$ & $-1.762(\mathrm{a})$ \\
\cline { 2 - 8 } & $\begin{array}{l}\text { Asymp. Sig. } \\
\text { (2-tailed) }\end{array}$ & $<.001^{* *}$ & $<.001^{* *}$ & $.001^{* *}$ & $<.001^{* *}$ & $<.001^{* *}$ & .078 \\
\hline \multirow{3}{*}{ Smokers } & $\mathbf{Z}$ & $-3.586(\mathrm{a})$ & $-3.917(\mathrm{a})$ & $-3.217(\mathrm{a})$ & $-3.704(\mathrm{a})$ & $-3.920(\mathrm{a})$ & $-3.217(\mathrm{a})$ \\
\cline { 2 - 8 } & $\begin{array}{l}\text { Asymp. Sig. } \\
\text { (2-tailed) }\end{array}$ & $<.001^{* *}$ & $<.001^{* *}$ & $.001^{* *}$ & $<.001^{* *}$ & $<.001^{* *}$ & $.001^{* *}$ \\
& & & & & & \\
\hline
\end{tabular}

Table 5: Paired Samples Test

\begin{tabular}{|c|c|c|c|c|c|c|c|c|c|c|}
\hline \multirow[t]{3}{*}{ Group } & & & \multicolumn{5}{|c|}{ Paired Differences } & \multirow[t]{3}{*}{$\mathbf{t}$} & \multirow[t]{3}{*}{ df } & \multirow{3}{*}{$\begin{array}{l}\text { Sig. (2- } \\
\text { tailed) }\end{array}$} \\
\hline & & & \multirow[t]{2}{*}{ Mean } & \multirow[t]{2}{*}{$\begin{array}{c}\text { Std. } \\
\text { Deviation }\end{array}$} & \multirow[t]{2}{*}{$\begin{array}{c}\text { Std. } \\
\text { Error } \\
\text { Mean }\end{array}$} & \multicolumn{2}{|c|}{$\begin{array}{c}95 \% \text { Confidence } \\
\text { Interval of the } \\
\text { Difference }\end{array}$} & & & \\
\hline & & & & & & Lower & Upper & & & \\
\hline $\begin{array}{l}\text { non } \\
\text { smokers }\end{array}$ & $\begin{array}{c}\text { Pair } \\
1\end{array}$ & $\begin{array}{l}\% \text { BONE } \\
\text { FILL 1 } \mathrm{m}-\% \\
\text { BONE FILL } \\
2 \mathrm{~m}\end{array}$ & -8.17895 & 9.52006 & 2.18405 & -12.76747 & -3.59042 & -3.745 & 18 & $.001 * *$ \\
\hline Smokers & $\begin{array}{c}\text { Pair } \\
1\end{array}$ & $\begin{array}{l}\text { \%BONE } \\
\text { FILL 1 m - \% } \\
\text { BONE FILL } \\
2 \mathrm{~m}\end{array}$ & -9.39737 & 11.60616 & 2.66264 & -14.99136 & -3.80338 & -3.529 & 18 & $.002 * *$ \\
\hline
\end{tabular}

(where - PPD:POCKET Probing Depth,CAL : Clinical Attachment Level,BL: Baseline,1m: One Month Recall Visit,2m: Two Month Recall Visit) 
Table 6: Mann-Whitney Test

\begin{tabular}{|l|l|l|l|l|l|l|}
\hline & $\begin{array}{l}\text { CHANGE } \\
\text { PPDblto1 }\end{array}$ & $\begin{array}{l}\text { CHANGE } \\
\text { PPDblto2 m }\end{array}$ & $\begin{array}{l}\text { CHANGE } \\
\text { PPD1 mto2 m }\end{array}$ & $\begin{array}{l}\text { CHANGECAL } \\
\text { blto1 m }\end{array}$ & $\begin{array}{l}\text { CHANGEC } \\
\text { ALbl to2 m }\end{array}$ & $\begin{array}{l}\text { CHANGECA } \\
\text { L1 mto2 m }\end{array}$ \\
\hline Mann-Whitney U & 144.000 & 140.500 & 178.500 & 110.000 & 157.000 & 156.000 \\
\hline Wilcoxon W & 334.000 & 330.500 & 368.500 & 300.000 & 347.000 & 346.000 \\
\hline Z & -1.175 & -1.296 & -.065 & -2.271 & -.751 & -.771 \\
\hline $\begin{array}{l}\text { Asymp. Sig. } \\
\text { (2-tailed) }\end{array}$ & .240 & .195 & .948 & $.023 *$ & .453 & .441 \\
\hline $\begin{array}{l}\text { Exact Sig. } \\
{[2 * \text { (1-tailed Sig.)] }}\end{array}$ & $.297(a)$ & $.246(\mathrm{a})$ & $.954(\mathrm{a})$ & $.040(\mathrm{a})$ & $.506(\mathrm{a})$ & $.488(\mathrm{a})$ \\
\hline
\end{tabular}

where - PPD:POCKET Probing Depth,CAL : Clinical Attachment Level,BL: Baseline,1m: One Month Recall Visit,2m: Two Months Recall Visit)

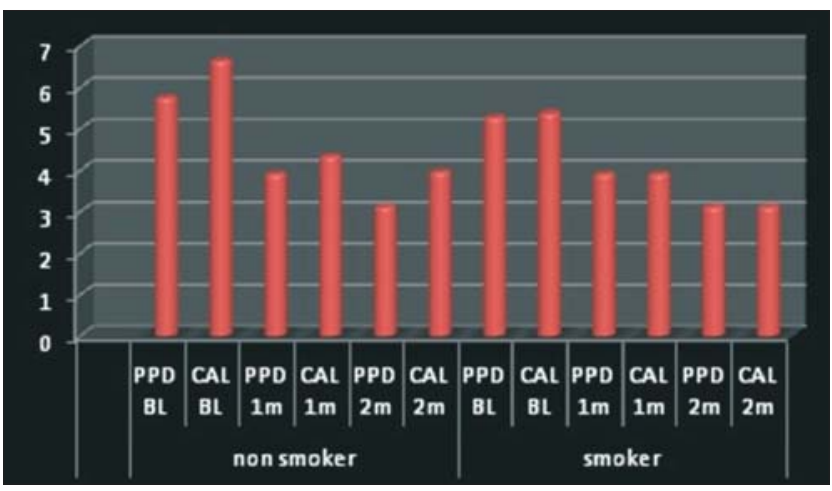

Figure 3: Showing Probing Pocket Depth, Clinical Attachment Level At Baseline, 1 Month and 2 Months of Smoker and Non-Smoker Patients

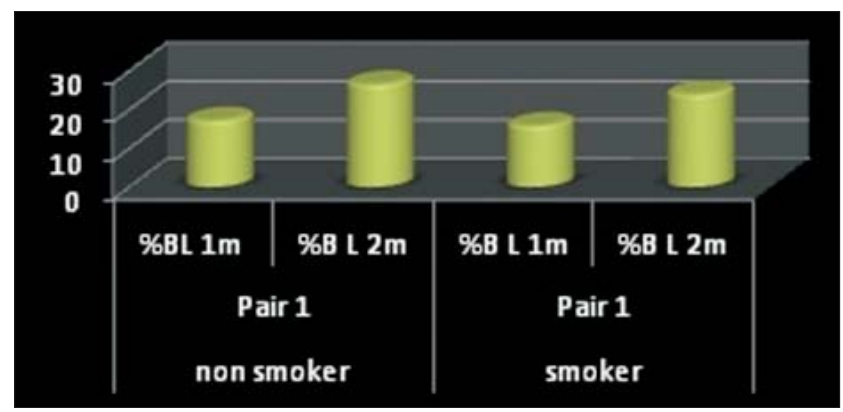

Figure 4: Showing percentage change in bone Level At Baseline, 1 Month And 2 Months of Smoker and Non-Smoker Patients

evaluation, all the subjects gave positive responses regarding the taste and flavour.

Local drug delivery of Azithromycin gel contributed to decrease in probing pocket depth, clinical attachment level and gain in alveolar bone. The apparent bone regeneration also raises the intriguing possibility that Azithromycin encourages bone formation once tissue inflammation has subsided.

\section{DISCUSSION}

Providing successful periodontal treatment for heavy smokers is often frustrating because they tend to have a less favourable therapeutic response to nonsurgical or surgical therapy compared to non-smokers. This study was designed with the aim of assessing the efficacy of local drug delivery of $0.5 \%$ azithromycin gel as an adjunct to non-surgical periodontal therapy in the treatment of chronic periodontitis in smoker subjects as compared to non smokers because of its high tissue concentration and increased patient compliance.

Tobacco smoking is considered one of the risk factors which can modify the periodontal response to microbial aggression, and was first studied by Pindborg. In a study by AR Pradeep, Smokers were reported to be more susceptible than non-smokers to advanced and aggressive forms of periodontitis. Haffajee et al. have reported significant clinical improvements in clinical parameters, following SRP, in subjects who had never smoked or who were past smokers, but similar results were not seen in current smokers. P. gingivalis, B. forsythus, and Treponema denticola were equally prevalent among current, past 
and 'never' smokers before therapy and decreased significantly post-SRP in all but the current smokers. Therefore, the use of antimicrobials as an adjunct to SRP for the treatment of chronic periodontitis in current smokers is imperative. ${ }^{22}$

AZM has been used in the systemic treatment of chronic periodontitis in smokers. In a study by Mascarenhas et al, AZM combined with SRP for the treatment of moderate to severe periodontitis in smokers provided significantly greater PD reduction and CAL gain in moderate and deep pockets, 6 months post-therapy as compared to SRP alone. Conversely, Dastoor et al. evaluated the adjunctive effect of systemic AZM in combination with periodontal surgery in smokers and demonstrated that in heavy smokers, adjunctive AZM in combination with periodontal surgery did not significantly enhance PD reduction or CAL gain. ${ }^{21}$ However, its clinical value may lie in more rapid wound healing, less short-term gingival inflammation, and sustained reduction of periopathogenic bacteria. In addition to this, systemically administered AZM becomes concentrated in fibroblasts and phagocytes and is transported to the infected site as a result of chemotactic effects exerted on the phagocytes.

Because of its high tissue concentration, tissue release is prolonged, leading to the delayed and gradual depletion of AZM. All of these properties make it an ideal agent to be investigated for local delivery in periodontal pockets. ${ }^{18}$

Advances in understanding the aetiology and pathogenesis of periodontal diseases have led to the innovation and subsequent acceptance of the use of these pharmacological agents in the management of chronic periodontitis. ${ }^{4}$

Local drug delivery systems have the ability to deliver the antibiotic to the target sites and achieve a high intrasulcular concentration with minimum systemic exposure. Moreover, these agents last for a sufficient duration to be effective. Compared to a systemic regimen, local delivery may offer important benefits in terms of minimal adverse reactions and patient compliance.,

The current study evaluated the clinical efficacy of $0.5 \% \mathrm{AZM}$ gel as an adjunct to SRP for the treatment of periodontal pockets in patients with chronic periodontitis who were current smokers and showed significant improvement in clinical parameters. To our knowledge, there have been no studies comparing the use of $0.5 \%$ AZM gel as LDD in the treatment of patients suffering chronic periodontitis, who were current smokers with non smokers.

Therefore, a direct comparison with other studies is not possible.

Previous studies have used 0.5\% AZM gel as LDD for 3 months in the treatment of chronic periodontitis patients, and reported significant improvement in the healing response compared to the placebo group. In a study, it was reported that there was a significant gain in clinical attachment level with the use of $0.5 \%$ clarithromycin as an adjunct to SRP for treating chronic periodontitis in smoker subjects and we found similar improvement in clinical parameters in the current study. ${ }^{4}$ Therefore, it can be proposed that direct subgingivally delivered AZM as an adjunct to SRP is a better approach for the treatment of periodontal pocket in current smokers with chronic periodontitis as compared to SRP alone.

We hypothesize that local drug delivery of AZM resulted in a high concentration of drug in the periodontal pocket, which might have penetrated into the periodontal tissues as well. This dual effect, on pocket microflora as well as on pathogens invading the tissue, might have resulted in enhanced clinical results without any systemic side effects and bacterial resistance. 


\section{CONCLUSION}

This clinical trial demonstrates that local delivery of $0.5 \%$ AZM gel into periodontal pockets of chronic periodontitis patients who were current smokers stimulated a significant improvement in clinical parameters which was comparable to that of non smokers. This can provide a new direction in the field of periodontal treatment in this special group of patients who are at greater risk for periodontal destruction. However, long-term multicentre randomized, controlled clinical trials using different vehicles and concentrations should be carried out to confirm the observations of our study.

In the present study Local drug delivery of Azithromycin gel contributed to decrease in probing pocket depth, gain in clinical attachment level and gain in alveolar bone. The apparent bone regeneration also raises the intriguing possibility that Azithromycin encourages bone formation once tissue inflammation has subsided.

\section{REFERENCES}

1. Pradeep AR, Bajaj P, Agarwal E, Rao NS, Naik SB, Kalra N. Local drug delivery of $0.5 \%$ azithromycin in the treatment of chronic periodontitis among smokers. Aus Dent J 2013; 58: 34-40.

2. Slots J. Subgingival microflora and periodontal disease. J Clin Periodontol 1979;6:351-352.

3. Moore WEC. Microbiology of periodontal disease. J Periodontal Res 1987;22:335-341.

4. Heitz-Mayfield LJ. Systemic antibiotics in periodontal therapy. Aust Dent J 2009;54:S96-S101.

5. Gelskey SC. Cigarette smoking and periodontitis: Methodology to assess the strength of evidence in support of a causal association. Community Dent Oral Epidemiol 1999;27:16-24.

6. Thomson WM, Slade GD, Beck JD, Elter JR, Spencer AJ, Chalmers JM. Incidence of periodontal attachment loss over 5 years among older South Australians. J Clin Periodontol 2004;31:119-125.

7. Johnson GK, Guthmiller JM. The impact of cigarette smoking on periodontal disease and treatment. Periodontol 2000 2007;44:178-194.
8. Martinez-Canut P, Lorca A, Magan R. Smoking and periodontal disease severity. J Clin Periodontol 1995; 22:743749.

9. Steinberg D, Friedman M, Soskolne A, Sela MN. A new degradable controlled release device for treatment of periodontal disease: in vitro release study. J Periodontol 1990;61:393-398.

10. Bergstrom J. Cigarette smoking as risk factor in chronic periodontal disease. Community Dent Oral Epidemiol 1989; $17: 245-247$.

11. Johnson GK, Hill M. Cigarette smoking and the periodontal patient. J Periodontol 2004;75:196-209.

12. Costabel U, Bross KJ, Reuter C, Ruhle KH, Matthys H. Alterations in immunoregulatory T-cell subsets in cigarette smokers. A phenotypic analysis of bronchoalveolar and blood lymphocytes. Chest 1986;90:39-44.

13. MacFarlane GD, Herzberg MC, Wolff LF, Hardie NA. Refractory periodontitis associated with abnormal polymorphonuclear leukocyte phagocytosis and cigarette smoking. J Periodontol 1992;63:908-913.

14. Johnson JD, Houchens DP, Kluwe WM, Craig DK, Fisher GL. Effects of mainstream and environmental tobacco smoke on the immune system in animals and humans: a review. Crit Rev Toxicol 1990;20:369-395.

15. Silverstein P. Smoking and wound healing. Am J Med 1992;93:22S-24S.

16. Hanes PJ, Schuster GS, Lubas S. Binding, uptake, and release of nicotine by human gingival fibroblasts. J Periodontol 1991;62: 147-152.

17. McDonald PJ, Pruul H. Phagocytic uptake and transport of azithromycin. Eur J Clin Microbiol Infect Dis 1991;10:828833.

18. Schentag JJ, Ballow CH. Tissue directed pharmacokinetics. Am J Med 1991;91:5S-11S.

19. Peters DH, Friedel HA, McTavish D. Azithromycin: a review of its antimicrobial activity, pharmacokinetic properties and clinical efficacy. Drugs 1992;44:750-799.

20. Pajukanta R, Asikainen S, Saarela M, Alaluusua S, Somer HJ. In vitro activity of azithromycin compared with that of erythromycin against Actinobacillus actinomycetemcomitans. Antimicrob Agents Chemother 1992;36:1241-1243.

21. Pajukanta R. In vitro antimicrobial susceptibility of Porphyromonas gingivalis to azithromycin, a novel macrolide. Oral Microbiol Immunol 1993;8:325-326.

22. Van Winkelhoff AJ, Herrera D, Winkel EG, Dellemijn- 
Kippuw N, Vandenbroucke-Grauls CM, Sanz M. Antibiotic resistance in subgingival microflora in patients with adult periodontitis. A comparative survey between Spain and the Netherlands (in Dutch). Ned Tijdschr Tandheelkd 1999;106:290-294.

23. Kamma JJ, Giannopoulou C, Vasdekis VGS, Mombelli A. Cytokine profile in gingival crevicular fluid of aggressive periodontitis: influence of smoking and stress. J Clin Periodontol 2004;31:894-902.
24. Shah NH, Railkar AS, Chen FC, Tarantino R, Kumar S, Murjani M. A biodegradable injectable implant for delivering micro and macromolecules using poly (lactic coglycolic) acid (PLGA) copolymers. J Control Release 1993;27:139-147.

25. Kamma JJ, Giannopoulou C, Vasdekis VGS, Mombelli A. Cytokine profile in gingival crevicular fluid of aggressive periodontitis: influence of smoking and stress. J Clin Periodontol 2004;31:894-902.

\section{Source of Support: Nil, Conflict of Interest: None Declared}

